\title{
Pre Extension Demonstration of Adapted Oat Varieties at Midland Areas of Guji Zone, Southern Oromia
}

\author{
Basha Kebede ${ }^{1, *}$, Dembi Korji ${ }^{1}$, Girma Amare ${ }^{2}$ \\ ${ }^{1}$ Oromia Agricultural Research Institute (IQQO), Bore Agricultural Research Center, Bore, Ethiopia \\ ${ }^{2}$ Department of Rural Development, Haramaya University, Dire Dawa, Ethiopia
}

Email address:

bsshkbd@gmail.com (B. Kebede)

${ }^{*}$ Corresponding author

To cite this article:

Basha Kebede, Dembi Korji, Girma Amare. Pre Extension Demonstration of Adapted Oat Varieties at Midland Areas of Guji Zone, Southern Oromia. International Journal of Animal Science and Technology. Vol. 5, No. 2, 2021, pp. 42-46. doi: 10.11648/j.ijast.20210502.13

Received: April 22, 2021; Accepted: June 15, 2021; Published: June 28, 2021

\begin{abstract}
Ethiopia is leading Africa in number of livestock though production and productivity of livestock at household level is low. In midland districts of Guji zone there was lack of improved forage varieties to feed livestock so that number of livestock ownership by household head is becoming low. To solve this problem adaptation study of oat varieties was conducted in the midlands. Since adaptation study did not ensure the accessibility of oat varieties for target area this demonstration was initiated to reach many farmers and agro-pastorals to evaluate improved oat varieties, to increase the knowledge and skills and to identify farmers/agro pastorals preference on improved oat varieties. Activity was done during 2019 and 2020 year and two improved oat varieties called Jasari and ILRI 5453 were demonstrated on $10 \mathrm{mx} 10 \mathrm{~m}$ areas of 8 experimental farmers and 7 agro-pastorals at Adola Rede and Wadera district respectively. Training, exchange visit and mini field day were used to increase farmers' and agro-pastorals' knowledge and skills on oat production. Observation, measurement, interview and focus group discussion were used to collect the data. The collected data was analyzed by $t$ test, mean and narration form. The result of this demonstration showed that more seed yield (37.47qt/ha), high dry biomass $(2.02 \mathrm{t} / \mathrm{ha})$ and more number of tillers (7.4) was obtained from ILRI 5453 than Jasari variety which gave a seed yield of $31.47 \mathrm{qt} / \mathrm{ha}, 1.58 \mathrm{t} / \mathrm{ha}$ dry biomass and5.8 number of tillers. Both varieties gave good seed yield at Wadera than Adola Rede district. This showed that oat production was more preferable at agro-pastoral area. T-test showed that there was significant difference at $(1 \%)$ in seed yield and dry biomass between demonstrated varieties. Demonstrated oat varieties were early matured and hence compatible for double cropping. Experimental farmers and agro-pastorals mentioned that yield, fresh biomass and dry biomass of oat were used for livestock feeding. It was palatable for cattle during vegetative stage and after harvesting so that oat production helped farmers and agropastorals both during wet and dry season feeding. ILRI 5453 was selected by farmers and agro-pastorals based on its yield, dry biomass and number of tillers. Therefore, ILRI 5453 oat was recommended for further promotion at midlands and agropastorals of Guji zone.
\end{abstract}

Keywords: Oat, Jasari, ILRI 5453, Demonstration, Guji

\section{Introduction}

Ethiopia has the highest livestock populations in Africa and accounts for $17 \%$ of cattle, $20 \%$ of sheep, $13 \%$ of goats and $55 \%$ of equines in Sub-Saharan Africa. Livestock production in Ethiopia is mainly of smallholder farming which accounts for $12 \%-16 \%$ national GDP, $30 \%$ of the total agricultural Gross Domestic Product (GDP), 16\% of national foreign currency earnings and $30 \%$ agricultural employment.
Ethiopia holds large potential for dairy development due to its large livestock population, the favorable climate for improved, high-yielding animal breeds, emerging market opportunity, improved policy environment for involvement of private sectors, and the relatively disease free environment for livestock [1].

Livestock development in Ethiopia are mainly limited by technical problem (insufficient and low quality feed sources) and institutional factors (poor linkages between research centers and end users, limited extension and financial 
services [1-4]. Due to these problems the production and productivity of livestock remains low. However, the Ethiopian government's second Growth and Transformation Program (GTP II) has envisaged to increasing by 2020 the productivity and total production of livestock through improving genetics and feed services [5].

Feed is the most important input in livestock production and its adequate supply throughout the year is an essential prerequisite for any substantial and sustained expansion in livestock production $[6,7]$. Feed shortages, poor quality of available feeds and nutrient deficiencies become more acute in the dry season in both the highlands and lowlands. To feed the increasing human population by continuous cereal growing, available grazing is on the decline. Cultivation of forage is not widely adopted and commercial feed production is not developed [6].

Pastoral and agro-pastoral production systems were not given due attention with respect to feed research and development interventions. Feeding guidelines for the different classes of animals and production systems based on available feed resources were scanty. Information on nutritional quality of major feed resources is limited. Improved forages required for on-farm production and research interventions are not adequately available [6].

Despite Guji zone is well known by potential of livestock production the major problem of Guji midland districts was lack of improved forage species. Due to this each year agro pastoral and agricultural offices of the zone were purchased feed resources from other zones due to lack of demonstration and multiplication of forage varieties in their zone. But purchasing feed system is not a sustainable option to solve lack of forage varieties unless adaptation research study followed by demonstration and scaling up of forage varieties were conducted in the area. With the prolonged drought effect the available feed is not sufficient for livestock production. As a result many livestock were died each year.

Reference [8] has mentioned that low accessibility of extension services and inadequacy of practical demonstrations as the causes of poor performance of the livestock extension service among small dairy holders. For the past decades, several forage crops have been tested in different agro-ecological zones and considerable efforts have been made to test the adaptability of different species of pasture and forage crops under varying agro-ecological conditions. So far, about 33 improved forage varieties have been registered and released for different agro-ecologies of the country [9]. As a result, improved forage crops have been grown and used in government ranches, state farms, farmers' demonstration plots, and dairy and fattening areas [10]. The most commonly grown forage crops were Oats, vetch, oats and vetch mixtures, fodder beet, Elephant grass, Rhodes, Sesbania, Leucaena, and tree-lucerne being the most common [11]. Oat is an important crop in marginal ecologies, for grain as well as for feed. It is adapted to a wide range of soil types and can perform better than other smallgrain cereals on acid soils. The farmers consider it as healthy food and suitable to human health. The farmers report that the cattle also prefer oat straw to tef straw [12].
Improved technologies and approaches to mitigate feed problem of farmers and agro pastorals should be developed and implemented. One approach could be demonstration of improved forage species to smallholder farmers and agro pastoralist. Therefore, this activity was initiated to demonstrate adapted oat varieties on farmers and agro pastorals land.

\section{Objectives}

1) To evaluate improved oat varieties on farmers and agro pastorals land

2) To increase the knowledge and skills of farmers and agro pastorals in production of oat varieties

3) To identify farmers/agro pastorals preference on demonstrated improved oat varieties

\section{Materials and Methods}

\subsection{Description of Study Areas}

Adola Rede district is $468 \mathrm{KM}$ away from the Addis Ababa to the South. The district is bordered by Ana Sora district in the North, Wadera district in the South and Odo Shakiso in the West and Girja district in the East directions. The district has altitude range of 1350-2340 meter above sea level, annual mean of $1000 \mathrm{~mm}$ rainfall and annual average of $28 \mathrm{C}^{\circ}$ of temperature. Mixed farming, mining and forest product production are the major livelihood of Adola Rede farmers. Adola district has diverse agro-ecologies which are suitable for production of different crops. The rainfall pattern of the district is bimodal for lowland and midland areas and unimodal for highland parts. Sandy, clay and silt are the major soils of Adola Rede district [13]. Wadera district is one of agro pastoral areas of Guji zone. The district is well known by livestock rearing and livestock production is the major farming activity of the district.

\subsection{Sites, Farmers and Agro-pastorals Selection}

The experiment was conducted at two midland districts of Guji Zone, Southern Oromia. Purposively, Adola Rede and Wadera districts were selected. Two kebeles per district was selected based on their potential livestock population. There were three experimental farmers/agro-pastorals from each kebele. Experimental farmers/agro-pastorals were selected based on their willingness to provide land for oat production.

\subsection{Research Design and Packages Used}

The activity was done during 2019 and 2020 year production season. Improved oat varieties of Jasari and ILRI 5453 were demonstrated on $10 \mathrm{~m} \mathrm{x} 10 \mathrm{~m}$ land of farmers/agro pastorals. $80 \mathrm{~kg} / \mathrm{ha}$ of seed rate of oat varieties were sown by $30 \mathrm{~cm}$ between rows and drilling of seed in the lines of rows. $100 \mathrm{~kg} / \mathrm{ha}$ of NPS and $50 \mathrm{~kg} / \mathrm{ha}$ of UREA was used at planting stage. Sowing was done early May month. Hand weeding, harvesting and threshing were done by farmers with technical support of Bore Agricultural 
Extension Researchers and Development Agents assigned in kebeles.

\subsection{Extension Methods Used}

Farmers, agro-pastorals, Development Agents and Subject Matter Specialists (SMSs) were trained on packages of oat production. This training enhanced farmers' and agropastorals' knowledge and skills on oat production. In addition, exchange visit and field day was organized for experience sharing and promotion of oat varieties in the study area. Experimental farmers were evaluated the performance of oat varieties on their field.

\subsection{Methods of Data Collection and Analysis}

Observation, measurement, interview and focus group discussion were used to collect the yield, biomass and farmers/agro-pastorals preference. The collected data was analyzed by $\mathrm{t}$ test, mean, range and narration form. Histogram and table was used to present the results.

\section{Results and Discussions}

\subsection{Capacity Building on Oat Production}

The main intention of agricultural extension is to enhance farmers' and agro-pastorals' knowledge and skills on the recommended agricultural technologies. There are many agricultural extension services conducted in Ethiopia but major extension services given at farm level are advice, training, exchange visit and field days [14]. Therefore, during this demonstration farmers and agro-pastorals knowledge and skills were enhanced by training, exchange visit and mini field day on demonstrated oat varieties (Table 1).

Table 1. Capacity building and number of stakeholders participated on oat demonstration.

\begin{tabular}{|c|c|c|c|c|}
\hline \multirow{2}{*}{ Capacity building methods } & \multirow{2}{*}{ Stakeholders } & \multicolumn{3}{|c|}{ Composition } \\
\hline & & Male & Female & Total \\
\hline \multirow{3}{*}{ Training } & Farmers and agro-pastorals & 75 & 30 & 105 \\
\hline & Das & 9 & 2 & 11 \\
\hline & SMSs & 7 & 3 & 10 \\
\hline \multirow[b]{2}{*}{ Exchange visit } & Farmers and agro-pastorals & 8 & 2 & 10 \\
\hline & Das & 1 & 1 & 2 \\
\hline \multirow{5}{*}{ Mini field day } & Farmers & 29 & 11 & 40 \\
\hline & Das & 3 & 1 & 4 \\
\hline & SMSs & 2 & 1 & 3 \\
\hline & Das & 3 & 1 & 4 \\
\hline & SMSs & 3 & - & 3 \\
\hline
\end{tabular}

\subsection{Yield and on Farm Performance of Oat Varieties}

Higher seed yield was obtained from ILRI 5453 (37.47 $\mathrm{qt} / \mathrm{ha})$ than Jasari variety (31.47 qt/ha). The yield result of this demonstration was lower than adaptation result where 49.2qt/ha and 33.3qt/ha for ILRI 5453 and Jasari respectively [7]. This yield difference between demonstration and adaptation might be due difference in management practices between farmers and biological researchers. The result of [15] indicated that grain yield performance of food oat genotypes range from 3045 to $3904 \mathrm{~kg} \mathrm{ha}^{-1}$. The performance of grain yield and yield related traits of oat genotypes were significantly affected by the main genetic, environmental and interaction of genotype by environment effects. In addition, $[12,16]$ studies showed that the grain yield performance was different in the oat genotypes across environments.

ILRI 5453 variety had higher dry biomass yield and number of tillers per plant than Jasari. Plant population and number of tillers is always a function of germination percentage. Number of tillers per plant of this research result was comparable to [17] who counted 7.64 on $80 \mathrm{~kg} /$ ha seed rate.

Table 2. Yield performance of oat varieties.

\begin{tabular}{lllllll}
\hline Varieties demonstrated & Parameters & N & Min & Max & Mean & Std. Dev. \\
\hline \multirow{3}{*}{ ILRI 5453 } & Seed yield (quintal/ha) & 15 & 30 & 49 & 37.47 & 6.32 \\
& Dry biomass (ton/ha) & 15 & 1.8 & 2.2 & 2.02 & 0.130 \\
& Number of tillers/plant & 15 & 5 & 10 & 7.40 & 1.68 \\
\multirow{4}{*}{ Jasari } & Seed yield (quintal/ha) & 15 & 26 & 35 & 31.47 & 2.74 \\
& Dry biomass yield (ton/ha) & 15 & 1.2 & 2 & 1.58 & 0.25 \\
& Number of tillers/plant & 15 & 4 & 8 & 5.80 & 1.14 \\
\hline
\end{tabular}

More seed yield was obtained from Wadera district (agro-pastoral area) than Adola Rede district (more agricultural area) in both ILRI 5453 and Jasari variety. This shows that oat varieties production were more suitable for agro-pastoral areas (figure 1). 


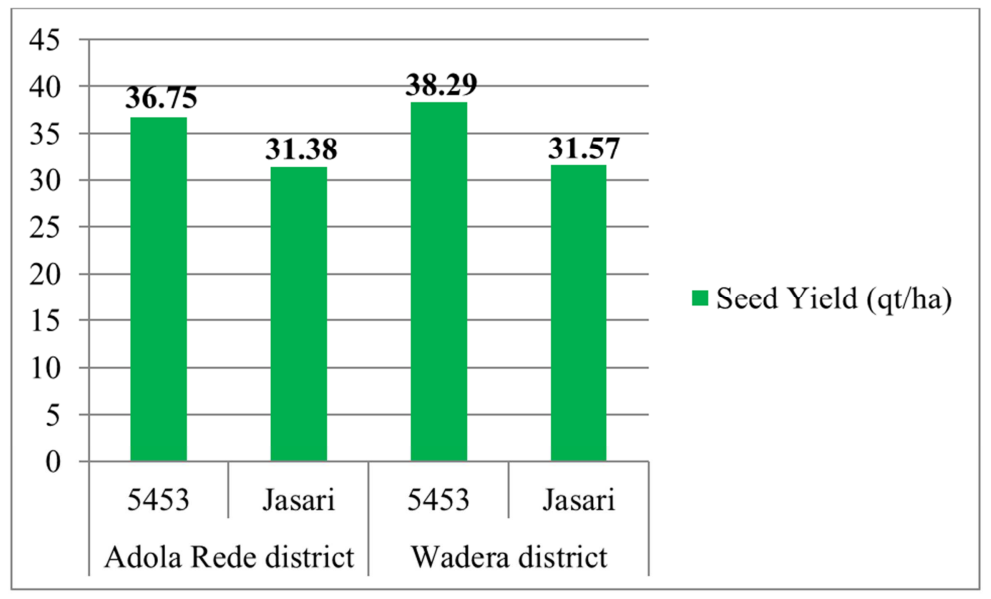

Figure 1. Seed yield across districts.

Independent $\mathrm{t}$ test was used to explain the mean yield difference between oat varieties. A significance value of.002 (less than.05) indicates that there was highly (at $1 \%$ ) significant difference yield between ILRI 5453 and Jasari variety. Based on the results of independent t-test $(p=.002$
$<.05)$, it was concluded that there was significant difference in yield between ILRI 5453 and Jasari variety in the study area. There was also a significant (at $1 \%$ ) difference in dry biomass yield of demonstrated varieties.

Table 3. Independent t test for seed yield and dry biomass mean between the two varieties.

\begin{tabular}{|c|c|c|c|c|c|}
\hline \multirow{2}{*}{ Parameters } & \multicolumn{5}{|c|}{ t-test for equality of means } \\
\hline & t & Df & Sig. (2-tailed) & Mean Difference & Std. Error Difference \\
\hline Seed yield & 3.371 & 28 & $.002^{* * *}$ & 6.000 & 1.780 \\
\hline Dry biomass & 5.813 & 28 & $.001^{* * *}$ & .434 & .075 \\
\hline
\end{tabular}

*** indicates significant at $1 \%$

\subsection{Farmers' and Agro Pastorals' Perception and Preference}

Demonstrated oat varieties were early matured forage. Though other forage stay long months and not used for double cropping the demonstrated oat varieties were compatible for double cropping when sown at early May month at midland districts of Guji Zone. Experimental farmers and agro-pastorals mentioned that yield, fresh biomass and dry biomass of oat were used for livestock feeding. It was palatable for cattle both during vegetative and after harvesting so that oat production helped farmers and agro-pastorals both during wet and dry season feeding. Though ILRI 5453 variety had more lodging status than Jasari it was preferred by farmers and agro-pastorals based on its higher dry biomass and yield than Jasari variety. Despite agronomic results farmers and agro-pastoral preference determines the acceptance of variety in their farming. Likewise [18] stated green fodder yield, standing vigor, non-lodging, disease tolerant, fast growth for oat varieties was the preference of farmers in their oat production.

More fertile land made ILRI 5453 variety to be lodge. Therefore, lodging of ILRI 5453 was determined by fertility of the land.

\section{Conclusions and Recommendations}

Pre extension demonstration of adapted oat varieties was conducted to evaluate yield performance and preference of farmers on oat production. Two improved varieties namely ILRI 5453 and Jasari were demonstrated on 8 experimental farmers and 7 agro-pastoralists. ILRI 5453 gave higher yield and dry biomass yield than Jasari variety. ILRI 5453 variety also had more number of tillers than Jasari. Experimental farmers and agro-pastorals mentioned that yield, fresh biomass and dry biomass of oat were used for livestock feeding. It was palatable for cattle both during vegetative and after harvesting so that oat production helped farmers as feeding both during wet and dry season. ILRI 5453 was selected by farmers and agro-pastorals based on its yield, dry biomass and number of tillers. Therefore, ILRI 5453 oat was recommended for further promotion at midlands and agropastorals of Guji zone. Besides, oat variety release for the study area should be based on farmers' and agro-pastorals' trait preference that could sustain oat production for livestock feeding. More fertile land leads lodging of oat so that site selection should be considered for oat production.

\section{Acknowledgements}

Author forward special thanks to Agricultural Growth Program II (AGP II) and Oromia Agricultural Research Institute for financial and Bore Agricultural Research Center for their logistic and material supports. Dr. Dagnachew Lule who motivated author to write this research proposal was kindly acknowledged. Farmers, agro-pastorals, Development Agents and SMSs who devoted for the success of this activity 
during the problem of covid-19 and insecurity of the area were heartily acknowledged.

\section{References}

[1] Tewodros Alemneh, Mebrate Getabalew and Dawit Akeberegn. (2019). Dairy Production in Ethiopia - Existing Scenario and Constraints. Biomedical Journal of Scientific and Technical Research. DOI: 10.26717/BJSTR.2019.16.002903 ISSN: 2574-1241, volume 16 (5); page 12304-12309.

[2] Hidosa D, Tesfaye Y. (2018) Assessment Study on Livestock Feed Resource, Feed Availability and Production Constraints in MaaleWoreda in South Omo Zone. J Fisheries Livest Prod 6: 269. doi: 10.4172/2332-2608.1000269.

[3] Emana M M, Ashenafi M, Getahun A. Opportunity and Constraints of Livestock Feed Resources in Abol and Lare Districts of Gambella Region, Ethiopia. Nutri Food SciInt J. 2017; 3 (4): 555620. DOI: 10.19080/NFSIJ.2017.03.555620.

[4] MOE, 2013. Major challenges and achievements in Ethiopian livestock production. Ministry of Agriculture, January 2013. Presentation. Ministry of Agriculture (MOA): Addis Ababa, Ethiopia.

[5] MOE, 2015. Ethiopia livestock master plan: Roadmaps for growth and transformation. Addis Ababa: Ministry of Agriculture and Nairobi, Kenya: ILRI.

[6] Jimma A, Tessema F, Gemiyo D, Bassa Z (2016) Assessment of Available Feed Resources, Feed Management and Utilization Systems in SNNPRS of Ethiopia. J Fisheries Livest Prod 4: 183. doi: 10.4172/2332-2608.1000183.

[7] Jabessa Teshale, Amare Zinash and Dejene Genet (2020). Adaptability Study of Oat (Avena Sativa) Genotypes for their Agronomic Performance and Nutritive Value in the Midland of East Guji Zone, Adola, Southern Oromia, Ethiopia. Asian Journal of Agriculture and Allied Sciences 3 (1): 9-12, 2020.

[8] Tegegne, A., Gebremedhin, B., Hoekstra, D., Belay, B., and Mekasha, Y. (2013). Smallholder dairy production and marketing systems in Ethiopia: IPMS experiences and opportunities for market-oriented development. Working Paper No. 31. ILRI: Addis, Ababa, Ethiopia.

[9] Getnet A, Solomon M, Fekede F, Seyoum B (2016). Animal Feeds Research in Ethiopia: Achievements, Challenges and Future Directions. Proceedings of the National Conference on
Agricultural Research for Ethiopian Renaissance held on January 26-27, 2016, in UNECA, Addis Ababa to mark the 50th Anniversary of the establishment of the Ethiopian Institute of Agricultural Research (EIAR).

[10] Mengistu A, Kebede G, Feyissa F, Assefa G (2017). Review on Major Feed Resources in Ethiopia: Conditions, Challenges and Opportunities. Academic Research Journal of Agricultural Science and Research 5 (3): 176-185.

[11] Endale Yadessa, Ulfina Galmessa, Lemma Fita and Temesgen Jembere (2021) Evaluation of the on-farm dairy technologies in Ethiopia: African Journal of Agricultural Research. Vol. 17 (4), pp. 697-704, April, 2021 DOI: 10.5897/AJAR2020.15341.

[12] Misganaw Ferede, Melle Tilahun, Zina Demsie, Ermias Abate, Molla Mekonnen, Gebremariam Asaye, Mequanint Andualem, Fentanesh Sendekie, Desalegn Getaneh, Yasin Taye, and Sefinew Wale (2020) Adaptation of Food Oat (Avena sativa L.) Genotypes in Amhara Region, Ethiopia. East African Journal of Sciences (2020) Volume 14 (2) 111-120.

[13] Basha Kebede., et al. "On Farm Demonstration and Evaluation of Improved Chickpea Varieties at Adola Rede, Guji Zone, Southern Oromia, Ethiopia”. Innovative Techniques in Agriculture 2.6 (2018): 531-537.

[14] Basha Kebede Peter N. Ewang Eric Ndemo. Okoyo (2017). Factors Affecting Productivity of Smallholder Potato Growers in Bore District, Guji Zone, Oromia Regional State, Ethiopia. Developing Country Studies www.iiste.org ISSN 2224-607X (Paper) ISSN 2225-0565 (Online) Vol. 7, No. 9, 2017.

[15] Amanuel Wada, Kassa Shawle and Deribe Gemiyo. 2019. Biomass yield and nutritional quality of different oat genotypes (Avena sativa) grown under irrigation condition in Sodo Zuriya District, Wolaita Zone, Ethiopia. Agricultural Research and Technology, 20 (4): 197-204.

[16] Dawit Abate and Mulusew Fikere. 2017. Performance of fodder oat (Avena sativa L.) genotypes for yield and yield attributes in the Highland of Bale. Journal of Biology, Agriculture and Healthcare, 7 (19): 29-33.

[17] Yidersal Erega, Fasil Nigusie, Getachew Animut 2020. Effects of Seed Rate and Nitrogen Fertilizer Rate on Growth and Biomass Yield of Oat (Avena Sativa L.) World J Agri\& Soil Sci. 4 (1): DOI: 10.33552/WJASS.2020.04.000580.

[18] Tamrat Dinkale, Birmaduma Gadisa and Muleta Debela. 2021. Registration and Releasing of "Bareda" Oat (Avena sativa L.) Variety for Mid and Highland of West Hararghe Zone, Oromia, Ethiopia. Int. J. Curr. Res. Aca. Rev. 9 (03), 81-88. doi: https://doi.org/10.20546/ijcrar.2021.903.008. 